\title{
Custos e shut-down point da atividade leiteira em Minas Gerais
}

\author{
Levy Heleno Fassio* \\ Ricardo Pereira Reis** \\ Luiz Carlos Takao Yamaguchi*** \\ Antônio João dos Reis****
}

Resumo - Através deste estudo, buscou-se avaliar os custos e identificar o shut-down point da atividade leiteira no Estado de Minas Gerais. Conforme as teorias da produção e do custo, o shut-down point representa o menor preço do produto em que a empresa poderia continuar produzindo, sendo suficiente apenas para cobrir os custos variáveis. Para preços situados abaixo desse ponto, não haveria oferta de leite pela empresa. Analisaram-se informações referentes a 574 produtores comerciais de leite provenientes de todas as mesorregiões do estado, tendo o período de estudo compreendido os anos agrícolas de 1995/96 a 2001/02. A análise do perfil econômico do setor demonstrou que os produtores pesquisados incorreram em altos custos por unidade produzida, sugerindo baixa eficiência técnica da atividade leiteira e falhas na administração do empreendimento. Os resultados econométricos evidenciaram a ocorrência de ganhos de escala e o shut-down point da atividade leiteira em Minas Gerais foi estimado em R $\$ 0,42$. Este valor

\footnotetext{
*Mestre em Administração - Pesquisador do Incaper. levy@incaper.es.gov.br

**Doutor em Economia Rural - Professor Titular do Departamento de Administração e Economia da Universidade Federal de Lavras. ricpreis@ufla.br

***Doutor em Economia Rural - Pesquisador da Embrapa/CNPGL. takao@cnpgl.embrapa.br

**** Mestre em Economia Rural - Professor Titular do Departamento de Administração e Economia da Universidade Federal de Lavras. ajreis@ufla.br
} 
representa o limite da resistência do pecuarista quanto ao declínio dos preços recebidos, ao qual o produtor estaria disposto a ofertar 1.299,45 litros de leite por dia, interrompendo a produção para preços menores.

Palavras-chave: leite, custos de produção, shut-down point.

\section{Classificação JEL: Q12}

Abstract - This work was carried out with the objective of both evaluating costs and identifying the shut-down point in milk production in Minas Gerais State. According to theories on both production and costs, the shut-down point is defined as the lowest price dairy farmers could afford supplying milk to market and still be able to cover their variable expenses. Data involving 574 commercial dairy farmers from all mesoregions in the state were analysed during the agricultural years 1995/6 - 2001/2. The economical profile analysis of the sector show that the cost of the product per unit was high. Economical results show both scale gain and an existing production level where the average variable cost is minimized. Therefore the shut-down point of milk production in Minas Gerais was estimated to be $R \$ 0,42$. At this estimated price 1.299,45 liters of milk per day can be supplied. In the case of lower prices production will not be able to continue.

Key words: milk, production costs, shut-down point.

JEl Classification: Q12

\section{Introdução}

O leite e seus derivados constituem uma valiosa fonte de calorias, cálcio, fósforo, vitaminas e proteínas de alta qualidade. Devido a este valor nutricional e ao acesso relativamente fácil da população de baixa renda, o leite pode desempenhar um importante papel na erradicação da fome, assegurando aos menos favorecidos uma alimentação barata e de qualidade.

Além do valor nutricional, é incontestável a sua importância sócioeconômica. O sistema agroindustrial do leite se faz presente em todas as 
regiões brasileiras, sendo um importante gerador de renda, tributos e empregos. Nogueira Netto et al. (2003) destacam que a pecuária de leite está presente em aproximadamente $40 \%$ das propriedades rurais do Brasil, sendo explorada predominantemente por pequenos e médios produtores.

A década de 1990 pode ser considerada um divisor de águas para a cadeia agroindustrial do leite. A partir deste período, profundas transformações ocorreram em todo o setor, as quais foram induzidas pela desregulamentação do mercado, política de abertura comercial, formalização do Mercosul, estabilidade macroeconômica, nova estrutura de produção e comercialização e também pelo crescente poder e discernimento do mercado consumidor, cada vez mais segmentado e exigente em qualidade, preços e variedade de produtos (Leite \& Gomes, 2001 e Zoccal, 2001). Estes fatos trouxeram um aumento da concorrência em todos os elos do agronegócio e os tem forçado a implementar novas estratégias, visando obter ganhos de competitividade (Souza, 2000 e Zoccal, 2001).

Com relação à produção primária, os reflexos desse novo ambiente manifestaram-se na maior especialização do setor produtivo, na redução do número de produtores, na melhoria da qualidade do produto, no aumento da escala de produção, no aumento da produtividade e na redução da sazonalidade (Leite \& Gomes, 2001).

Destaca-se que o setor produtivo, por representar o elo mais frágil da cadeia, é aquele que mais intensamente tem sofrido as conseqüências das novas exigências do mercado. Alencar et al. (2001) afirmam que ocorrem, no agronegócio do leite, situações de mercado típicas de concorrência imperfeita, em que as relações estabelecidas entre o setor agropecuário e os setores à montante e à jusante assumem, respectivamente, características de oligopólio e oligopsônio. Esta situação leva os produtores rurais a disporem de poucos recursos para negociarem seus interesses no interior da cadeia produtiva do leite, inclusive à menor capacidade de negociação de preços. Registra-se que, no período 19901999, o preço do leite recebido pelos produtores decresceu, em média, $7,5 \%$ ao ano (Yamaguchi et al., 2001).

Diante desse cenário, uma das alternativas de que dispunham os produtores de leite para se manterem na atividade foi a redução dos custos de produção, cujo conhecimento é essencial para o efetivo controle da empresa rural e para o processo de tomada de decisão. 
Entretanto, a grande questão que se levanta é até que ponto os pecuaristas são capazes de modificar a sua estrutura produtiva, alcançando ganhos de produtividade, aumento de escala e a conseqüente redução de custos. Deve-se indagar, portanto, se os produtores de leite reúnem os recursos financeiros e as condições necessárias para implementar tais mudanças e o quanto podem resistir à queda dos preços recebidos. Em outras palavras, é preciso que se estime o preço mínimo necessário para manter o produtor de leite na atividade.

O problema da resistência quanto ao declínio dos preços do leite pode ser avaliado por meio do conceito de shut-down point. Conforme Nicholson (1998), este corresponde ao custo variável médio mínimo de produção e representa o menor preço do produto em que a empresa poderia continuar em atividade. A sua relevância assenta-se sobre o fato de, no curto prazo, a oferta cair a zero para qualquer preço abaixo desse custo.

O presente estudo objetivou avaliar os custos e identificar o shutdown point da atividade leiteira em Minas Gerais. Especificamente, buscou-se estimar a função de custo da produção leiteira neste estado e identificar o preço mínimo necessário para que a empresa continue produzindo leite, assim como a quantidade produzida ao referido preço.

\section{Metodologia}

\subsection{Modelo teórico}

O presente trabalho fundamenta-se nos princípios da teoria da empresa, compreendidos pelas teorias da produção e do custo, as quais fornecem explicações sobre como as empresas tomam decisões buscando a otimização na alocação dos recursos produtivos. As condições físicas do processo produtivo, o preço dos fatores e a busca de eficiência econômica pelo empresário estabelecem o custo de produção da empresa, que pode ser expresso na forma funcional:

$C T=f(q)$,

sendo CT o custo total e q a quantidade produzida. 
Ao se analisar os custos, é importante fazer a distinção entre curto e longo prazo. No curto prazo, a empresa não é capaz de variar as quantidades de alguns recursos utilizados, o que leva à classificação dos recursos em fixos e variáveis. As despesas deles originadas são, respectivamente, os custos fixos e variáveis.

A curto prazo, os custos fixos e variáveis, para diferentes quantidades de produto, são as partes componentes dos custos totais. Nesse sentido, os conceitos de custos médios abrangem o custo total médio (CTMe), o custo fixo médio (CFMe) e o custo variável médio (CVMe). Algebricamente, para minimizar a função de custo variável médio, as condições necessária e suficiente são:

$\frac{\mathrm{dCVMe}}{\mathrm{dq}}=0 \quad$ e $\frac{\mathrm{d}^{2} \mathrm{CVMe}}{\mathrm{dq}^{2}}>0$

Outro indicador econômico de interesse neste trabalho é o custo marginal (CMa), definido pela expressão:

$\mathrm{CMa}=\frac{\mathrm{dCT}}{\mathrm{dq}}$

Uma propriedade importante da curva de custo marginal é que esta intercepta as curvas de custo total médio e custo variável médio em seus respectivos pontos mínimos. Isto equivale a dizer que o custo marginal iguala-se ao custo total médio e ao custo variável médio para os níveis de produção em que estes são mínimos.

A quantidade ótima de produto, aquela que maximiza os lucros, pode ser encontrada a partir das condições marginais para a maximização do lucro em função do produto:

$\pi=\mathrm{RT}-\mathrm{CT}$,

em que $\pi=$ lucro; $\mathrm{RT}=$ receita total e $\mathrm{CT}=$ custo total.

Sendo RT = r(q) e CT = c(q), a condição necessária para se maximizar o lucro consiste em:

$\frac{\mathrm{d} \pi}{\mathrm{dq}}=\mathrm{r}^{\prime}(\mathrm{q})-\mathrm{c}^{\prime}(\mathrm{q})=0 \quad \therefore \quad \mathrm{r}^{\prime}(\mathrm{q})=\mathrm{c}^{\prime}(\mathrm{q}) \quad \therefore \mathrm{RMa}=\mathrm{CMa}$, 
em que $\mathrm{RMa}=$ receita marginal e $\mathrm{CMa}=$ custo marginal, considerando as condições suficientes atendidas.

Na análise de produção e custo deste trabalho, pressupõe-se que a empresa opere num mercado em que não pode influenciar o preço de qualquer produto ou recurso utilizado no processo produtivo. Desse modo, a receita marginal da empresa é igual ao próprio preço do produto comercializado $\left(\mathrm{RMa}=\mathrm{p}_{\mathrm{q}}\right.$ ) e o ponto de equilíbrio é encontrado quando a linha de preço corta a curva do custo marginal $\left(\mathrm{CMa}=\mathrm{p}_{\mathrm{q}}\right)$. Assim, o produtor conduzirá o processo produtivo enquanto o preço do produto for igual ou superior ao custo variável médio. Quando a linha de preço, $\mathrm{p}_{\mathrm{q}}$, cai abaixo do custo variável médio, o empresário está perdendo todos os custos fixos e parte dos variáveis.

Nesse sentido, o ponto mínimo da curva de custo variável médio representa o menor preço do produto em que a empresa poderia continuar produzindo. Isto significa que a oferta cai a zero para qualquer preço abaixo do custo variável médio, ou seja, abaixo do shut-down point (Figura 1). Portanto, para o curto prazo, o shut-down point corresponde ao limite da resistência dos produtores quanto ao declínio dos preços recebidos e a parte hachurada da curva de custo marginal (Figura 1), a curva de oferta da empresa (Ferguson, 1999; Nicholson, 1998; Pindyck \& Rubinfeld, 2002).

Figura 1 - Curvas de custo total médio (CTMe), custo variável médio (CVMe), custo marginal (CMa) e oferta da empresa

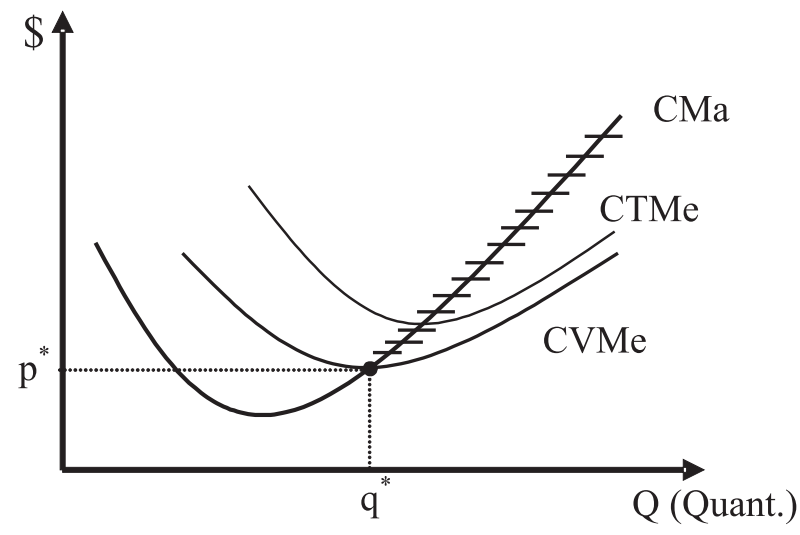




\subsection{Modelo analítico}

Para atender aos objetivos propostos neste trabalho, estimou-se um modelo de custo total expresso como uma função cúbica, sendo representada a seguir:

$C T=\beta_{0}+\beta_{1} q+\beta_{2} q^{2}+\beta_{3} q^{3}+\varepsilon$,

em que $\varepsilon=$ termo do erro que se admite possuir as propriedades usuais; $\beta_{0}, \beta_{1}, \beta_{2}$ e $\beta_{3}=$ parâmetros a serem estimados; $q=$ produção anual (litros) e $\mathrm{CT}=$ custo total $(\mathrm{R} \$$ ).

Para que o modelo cúbico seja coerente com a teoria do custo, o coeficiente do termo cúbico $\left(\beta_{3}\right)$ deve ser positivo e o do termo quadrático $\left(\beta_{2}\right)$, negativo, o que gera curvas de custo marginal, custo total médio e custo variável médio em forma de "U". Devido a esta conformação, o nível de produção, q, onde o custo variável médio alcança o seu ponto mínimo, shut-down point, pôde ser calculado a partir da função de custo.

O modelo econométrico de custo foi ajustado pelo método dos mínimos quadrados ordinários (MQO) e efetuou-se a avaliação da qualidade do ajustamento por meio do coeficiente de determinação $\left(\mathrm{R}^{2}\right)$. Também se empregou a estatística F para avaliar a significância da relação entre o custo total e o nível de produção. Na avaliação dos coeficientes estimados, além da coerência dos sinais, o teste $t$ mediu a significância destes para o modelo.

\subsection{Região do estudo e dados básicos}

Neste trabalho, analisaram-se informações referentes a 574 observações ou produtores comerciais de leite, distribuídos em todas as mesorregiões do Estado de Minas Gerais: Noroeste (11 produtores), Norte (8 produtores), Jequitinhonha (8 produtores), Vale do Mucuri (1 produtor), Triângulo/Alto Paranaíba (133 produtores), Central Mineira (14 produtores), Metropolitana (49 produtores), Vale do Rio Doce (45 produtores), Oeste (6 produtores), Sul/Sudoeste ( 96 produtores), Campo das Vertentes (91 produtores) e Zona da Mata (112 produtores). Estes dados foram cedidos pela EMATER-MG e se referem aos anos agrícolas 
de 1995/96 a 2001/02. A composição do grupo de produtores originouse da seleção intencional destes em função da disponibilidade de dados, resultante da receptividade dos produtores quanto ao programa de Administração Rural conduzido pela EMATER-MG.

É importante registrar que, na presente pesquisa, utilizou-se uma combinação de dados de seção cruzada e série temporal. Além disso, muitas das propriedades participantes do projeto não foram acompanhadas durante todo o período de análise. Isto significa que alguns produtores deixaram de participar do programa da EMATER-MG, enquanto outros ingressaram após o ano de 1995.

As variáveis empregadas no modelo foram o custo total, expresso em reais e corrigido pelo Índice Geral de Preços (IGP-DI), com base em 1998, e a quantidade produzida, expressa em litros de leite por ano. Especificamente, as informações cedidas consistiram de: a) inventário da propriedade para terra, benfeitorias, máquinas, equipamentos, veículos e animais; b) índices zootécnicos, produção e produtividade; c) levantamento dos componentes de custos: despesas com insumos e serviços e depreciação do capital investido em benfeitorias, forrageiras, máquinas, equipamentos e veículos. A remuneração do fator terra resultou do valor do aluguel por hectare, segundo a região onde se localizavam as propriedades. Para os demais fatores de produção, incluindo-se os animais produtivos (vacas e novilhas), estipulou-se, como custo do capital empatado na atividade leiteira, a taxa de juros de $6 \%$ a.a., conforme metodologia proposta por Reis (2002).

Na representação dos sistemas de produção, optou-se pela estratificação dos produtores conforme a produção diária de leite (SEBRAE - FAEMG, 1996), como pode ser observado na Tabela 1.

Tabela 1 - Freqüência de produtores de leite estudados por estrato de produção diária e distribuição da produção, período 1995/96 a 2001/02, Minas Gerais.

\begin{tabular}{lccc}
\hline Estrato de Produção & $N^{0}$ Produtores & Percentual da Amostra (\%) & $\begin{array}{c}\text { Percentual da } \\
\text { Produção (\%) }\end{array}$ \\
\hline Até 50 L & 36 & 6,27 & 0,81 \\
De 51 a 250 L & 354 & 61,67 & 32,52 \\
Acima de 250 L & 184 & 32,06 & 66,67 \\
\hline Total & 574 & 100 & 100 \\
\hline
\end{tabular}

Fonte: Dados da pesquisa. 


\section{Resultados e Discussão}

\subsection{Resultados econômicos dos produtores de leite em estudo}

A Tabela 2 apresenta a participação da receita obtida com a venda de leite em relação à receita bruta da atividade leiteira. Verifica-se que a participação da receita proveniente da comercialização de leite, considerando-se todo o grupo de produtores, foi de $81,11 \%$. Observa-se que os valores obtidos para os três estratos de produção situaram-se bastante próximos à média geral. Os estratos de pequenos, médios e grandes produtores auferiram, respectivamente, $84,55 \%, 79,77 \%$ e $83,00 \%$ de sua receita com a comercialização de leite.

Tabela 2 - Composição da renda da pecuária leiteira com a venda de leite por estrato de produção diária, período 1995/96 a 2001/02, Minas Gerais.

\begin{tabular}{lcc}
\hline \multirow{2}{*}{ Estrato de Produção } & \multicolumn{2}{c}{ Fontes de Renda (\%) } \\
\cline { 2 - 3 } & Leite & Outros Produtos $^{1}$ \\
\hline Até 50 L & 84,55 & 15,45 \\
De 51 a 250 L & 79,77 & 20,23 \\
Acima de 250 L & 83,00 & 17,00 \\
\hline Geral & 81,11 & 18,89 \\
\hline
\end{tabular}

Fonte: Dados da pesquisa.

${ }^{1}$ Inclui venda de animais, queijos, esterco, etc.

A estimativa dos custos revelou que os produtores pesquisados incorreram em altos custos por unidade produzida. Tanto o volume de produção quanto a produtividade são fatores que exercem grande influência sobre o comportamento dos custos. Relação esta que pode ser visualizada na Tabela 3, seja considerando o percentual dos custos fixos em relação ao custo total ou os custos unitários da produção de leite. Analisando-se a Tabela 3, percebe-se que a relação custo fixo/ custo total apresenta-se declinante com o aumento da produtividade e da escala de produção. 
Tabela 3 - Produtividade média por vaca em lactação, percentual do custo fixo sobre o custo total e custo total médio por estrato de produção diária, período 1995/96 a 2001/02, Minas Gerais.

\begin{tabular}{|c|c|c|c|c|c|}
\hline \multirow{2}{*}{\multicolumn{2}{|c|}{ Discriminação }} & \multicolumn{4}{|c|}{ Estrato de Produção (L/dia) } \\
\hline & & Até 50 & De 51 a 250 & Acima de 250 & Geral \\
\hline \multirow{2}{*}{ Produtividade } & Médias (L/dia) & $6,45 \mathrm{a}$ & $10,50 \mathrm{~b}$ & $14,05 \mathrm{c}$ & 11,39 \\
\hline & $\mathrm{CV}^{1}(\%)$ & 50,54 & 51,53 & 41,54 & 51,09 \\
\hline \multirow{2}{*}{$\mathrm{CFT} / \mathrm{CT}$} & Médias (\%) & $43,45 \mathrm{a}$ & 39,33 a b & $35,46 \mathrm{~b}$ & 38,35 \\
\hline & $\mathrm{CV}^{1}(\%)$ & 29,37 & 30,52 & 30,46 & 30,95 \\
\hline \multirow{2}{*}{ СТМе } & Médias (R\$/L) & $0,70 \mathrm{a}$ & $0,57 \mathrm{~b}$ & $0,47 \mathrm{c}$ & 0,54 \\
\hline & $\mathrm{CV}^{1}(\%)$ & 30,27 & 32,99 & 32,49 & 34,46 \\
\hline
\end{tabular}

Fonte: Dados da pesquisa.

Médias seguidas de mesma letra, na linha, são estatisticamente iguais pelo teste de Tukey, a $5 \%$ de probabilidade.

${ }^{1}$ Coeficiente de variação.

Os resultados demonstram que a utilização de um nível tecnológico mais elevado, expresso pelos maiores índices de produtividade, refletese na redução dos custos unitários à medida que os produtores obtêm ganhos de produtividade. Isto pode ser comprovado analisando-se o decréscimo do custo total médio à medida que aumentam a produtividade e a escala de produção (Tabela 3 ).

Na Tabela 4, resume-se o desempenho econômico da atividade leiteira em estudo, especificando-se os valores médios dos custos de produção unitários do leite, bem como o resultado da receita por unidade de produção. Tais custos situaram-se bastante próximos aos obtidos por diversos autores que estudaram a pecuária leiteira em Minas Gerais, os quais apresentam custos de produção variando de $\mathrm{R} \$ 0,39$ a $\mathrm{R} \$ 0,69$ por litro de leite (Reis et al., 2001; Marques et al., 2002; Lopes et al., 2004; Gomes, 2005).

Observa-se que, em todos os estratos, a receita média dos produtores (RMe) foi insuficiente para cobrir os seus custos totais médios (CTMe), sugerindo ineficiência na alocação dos recursos produtivos. De fato, trabalhos recentes desenvolvidos no estado têm apontado ineficiência técnica e alocativa na atividade leiteira, o que tem acarretado custos elevados de produção, ou seja, ineficiência econômica (Ferreira Júnior \& Cunha, 2004; Tupy et al., 2005). 
Tabela 4 - Desempenho econômico das empresas produtoras de leite pesquisadas segundo estrato de produção diária, período 1995/96 a 2001/02, Minas Gerais.

\begin{tabular}{|c|c|c|c|c|c|}
\hline \multirow{2}{*}{\multicolumn{2}{|c|}{ Receitas e Custos }} & \multicolumn{4}{|c|}{ Estrato de Produção (L/dia) } \\
\hline & & \multirow{2}{*}{$\begin{array}{l}\text { Até } 50 \\
0,39 \text { a }\end{array}$} & \multirow{2}{*}{$\frac{\text { De } 51 \text { a } 250}{0,34 \mathrm{~b}}$} & \multirow{2}{*}{$\frac{\text { Acima de } 250}{0,30 \mathrm{~b}}$} & \multirow{2}{*}{$\frac{\text { Geral }}{0,33}$} \\
\hline cVMe & Médias (R \$ L) & & & & \\
\hline Conte & $\mathrm{CV}^{1}(\%)$ & 36,97 & 34,61 & 34,62 & 35,51 \\
\hline \multirow{2}{*}{ CTMe } & Médias (R \$ L) & $0,70 \mathrm{a}$ & $0,57 \mathrm{~b}$ & $0,47 \mathrm{c}$ & 0,54 \\
\hline & $\mathrm{CV}^{1}(\%)$ & 30,27 & 32,99 & 32,49 & 34,46 \\
\hline \multirow{2}{*}{ CopVMe } & Médias (R \$ L) & $0,38 \mathrm{a}$ & $0,33 \mathrm{~b}$ & $0,29 \mathrm{~b}$ & 0,32 \\
\hline & $\mathrm{CV}^{1}(\%)$ & 36,97 & 34,61 & 34,62 & 35,51 \\
\hline \multirow{2}{*}{ CopTMe } & Médias (R $\$$ L) & $0,51 \mathrm{a}$ & $0,43 \mathrm{~b}$ & $0,37 \mathrm{c}$ & 0,42 \\
\hline & $\mathrm{CV}^{1}(\%)$ & 34,79 & 33,53 & 34,16 & 35,10 \\
\hline \multirow{2}{*}{$\mathrm{RMe}^{2}$} & Médias (R \$L) & $0,33 \mathrm{a}$ & $0,36 \mathrm{ab}$ & $0,38 \mathrm{~b}$ & 0,36 \\
\hline & $\mathrm{CV}^{1}(\%)$ & 31,60 & 29,00 & 25,72 & 28,20 \\
\hline
\end{tabular}

Fonte: Dados da pesquisa.

Médias seguidas de mesma letra, na linha, são estatisticamente iguais pelo teste de Tukey, a $5 \%$ de probabilidade.

${ }^{1}$ Coeficiente de variação.

${ }^{2}$ Inclui venda de leite, animais e subprodutos.

Em vista do cenário apresentado, é útil empregar o custo operacional para a análise da rentabilidade do empreendimento. Conforme Reis (2002), o custo operacional é o custo de todos os recursos que exigem desembolso monetário por parte da atividade produtiva para a sua recomposição, tais como gastos com insumos, mão-de-obra, manutenção e despesas gerais, incluindo-se também as depreciações dos recursos fixos. O custo operacional total é dividido em custo operacional fixo, composto pelas depreciações, e custo operacional variável, constituído pelos desembolsos ou despesas de giro. Somando-se o custo operacional ao custo alternativo ou de oportunidade, obtém-se o custo econômico.

Observa-se, na Tabela 4, que a receita média do estrato de pequenos produtores foi menor que o seu custo operacional variável médio (CopVMe), indicando a ocorrência de subsídio à atividade. Entretanto, quando se analisou o gasto anual com mão-de-obra familiar, onde se inclui também a retirada do produtor, verificou-se um gasto médio de $\mathrm{R} \$$ 0,14/litro, valor este que somado à receita média é capaz de cobrir o custo variável da atividade. Esta é, pois, a lógica dos produ- 
tores, que normalmente não consideram tais gastos como custos, mas sim como receitas.

Com relação ao estrato de médios produtores, a receita média foi inferior ao custo operacional total médio (CopTMe), mas ainda superior ao custo operacional variável médio (CopVMe). Isto indica que a atividade está cobrindo todos os custos operacionais variáveis (desembolsos ou despesas de giro) e somente parte do custo operacional fixo (depreciações). Nestas circunstâncias, o empreendimento poderá se sustentar apenas no curto prazo, não se considerando a remuneração do capital e a reposição de parte dos recursos fixos. Estes resultados evidenciam, em síntese, um processo de descapitalização que coloca em risco a permanência de pequenos e médios produtores na atividade leiteira em Minas Gerais.

Já no estrato de grandes produtores, a receita média (RMe) superior ao custo operacional total médio (CopTMe) demonstra que a atividade está obtendo um retorno financeiro sobre o seu investimento, ainda que inferior aos possíveis de se obter em outras alternativas de emprego do capital. Isto significa que a empresa está cobrindo todos os custos operacionais, fixos e variáveis, mas rendendo menos que o valor alternativo ou de oportunidade.

\subsection{Resultados econométricos}

Os resultados do ajustamento estatístico do modelo de custo, expresso como uma função cúbica, estão sintetizados na Tabela 5. A equação empírica na forma cúbica foi selecionada por atender aos objetivos do presente trabalho e, principalmente, devido à qualidade estatística dos indicadores, uma vez que resultaram em valores elevados de coeficiente de determinação e estatística $\mathrm{F}$, bem como devido à significância dos parâmetros de interesse para a estimativa do shut-down point e à coerência dos sinais em relação à teoria econômica. Também os modelos na forma quadrática e de potência foram testados, sendo, porém, desconsiderados em razão da menor qualidade do ajustamento ou por apresentarem sinais incoerentes, além de não atenderem plenamente aos objetivos propostos. 
Tabela 5 - Estimativa da função de custo total para a produção leiteira em Minas Gerais, período 1995/96 a 2001/02.

\begin{tabular}{lcccc}
\hline Parâmetros & Estimativas & Erro padrão & $\mathrm{t}$ & $\mathrm{p}>\mathrm{t}$ \\
\hline$\beta_{0}$ & 441,73911 & 2198,769 & 0,200903 & 0,841 \\
$\beta_{1}$ & 0,554910 & 0,037842 & 14,66393 & 0,000 \\
$\beta_{2}$ & $-5,35583 \mathrm{E}-07$ & $1,32 \mathrm{E}-07$ & $-4,06778$ & 0,000 \\
$\beta_{3}$ & $5,64604 \mathrm{E}-13$ & $1,03 \mathrm{E}-13$ & 5,464777 & 0,000 \\
\hline & $\mathrm{R}^{2}=0,8545$ & $\mathrm{~F}=1115,579$ & $\operatorname{SigF}(0,0000)$ & \\
\hline
\end{tabular}

Fonte: Dados da pesquisa.

Os resultados estatísticos indicam que todos os coeficientes de interesse para a estimativa do shut-down point são, significativamente, diferentes de zero a $1 \%$ de probabilidade, exceto o coeficiente $\beta_{0}$, não necessário para o referido cálculo, que foi estatisticamente não significativo. Pode-se observar também a coerência dos sinais quanto à teoria econômica, assim como o elevado valor da estatística F, indicando que a relação entre o custo total e a quantidade produzida foi significativa a $1 \%$ de probabilidade. O coeficiente de determinação estimado demonstra que $85,45 \%$ das variações ocorridas na estimativa do custo total foram explicadas pelo volume de leite produzido.

A partir do conhecimento da função de custo total, foi possível derivar as funções de custo total médio (CTMe), custo variável médio (CVMe) e custo marginal (CMa). Em razão das propriedades apresentadas anteriormente, estas são funções de segundo grau. Portanto, decrescem inicialmente, alcançam um mínimo e voltam a crescer com o aumento do nível de produção. Tal conjunto de funções pode ser visualizado geometricamente a partir da Figura 2.

Considerando-se o fato de a maximização dos lucros ocorrer em um nível de produção em que o custo marginal é crescente e igual à receita marginal, e admitindo-se que o produtor de leite opere num mercado em que não pode influenciar o preço do produto, pode-se concluir que o mesmo continuará produzindo enquanto o preço do leite for maior ou igual ao custo variável médio. Se este preço cair abaixo do custo variável, o pecuarista interromperá a produção, uma vez que não estaria nem mesmo recuperando o capital de giro empregado na atividade leiteira. Logo, o ponto mínimo da curva de custo variável médio, deno- 
minado shut-down point, representa o menor preço do produto em que a empresa poderia continuar produzindo.

Figura 2 - Representação das funções de custo total médio (CTMe), custo variável médio (CVMe) e custo marginal $(\mathrm{CMa})$ para a produção leiteira do Estado de Minas Gerais, período 1995/96 a 2001/02.

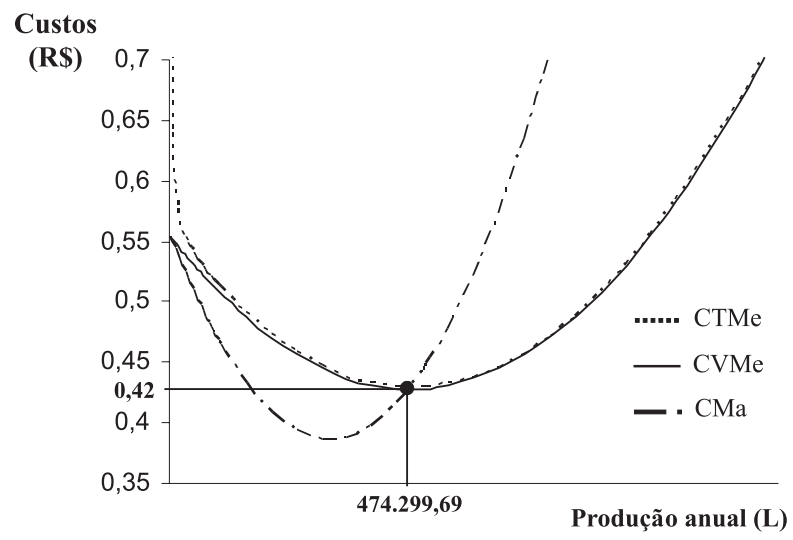

Analisando-se a Figura 2, verifica-se que o shut-down point da atividade leiteira em Minas Gerais corresponde a R \$ 0,42. Este é, portanto, o menor preço que o produtor mineiro poderia receber pelo leite, ou seja, o limite de sua resistência quanto ao declínio dos preços recebidos. Corroboram este resultado os dados apresentados por Reis et al. (2001), Lopes et al. (2004) e Gomes (2005), os quais situaram o custo variável no estado entre $R$ \$ 0,31 e $R$ \$ 0,42/litro.

A este valor, o pecuarista estaria disposto a ofertar 474.299,6862 litros de leite por ano, o que corresponde a uma produção de 1.299,45 litros/dia. Para qualquer preço abaixo de $\mathrm{R} \$ 0,42$ não haveria, teoricamente, oferta de leite. Neste sentido, a partir do shut-down point, a curva de custo marginal representa a curva de oferta da empresa leiteira para o Estado de Minas Gerais (Figura 2).

Os resultados apresentados demonstram a necessidade das empresas buscarem escala de produção, o que as levaria a obter maior eficiência econômica. Isto fica evidente considerando-se que um custo variável médio de $\mathrm{R} \$ 0,42$ só pode ser obtido com uma produção diária de aproximadamente 1.300 litros. Desse modo, somente os grandes 
produtores, ou aqueles que dispõem de recursos para aumentar a capacidade produtiva de suas empresas, teriam condições de se manter na atividade leiteira.

Nesse sentido, seria interessante também estimar o shut-down point para cada estrato de produção diária. Entretanto, não foi possível ajustar nenhum modelo específico, devido à grande dispersão dos dados dentro de cada estrato produtivo, assim como devido à baixa qualidade dos ajustamentos estatísticos.

Em razão do grande volume de recursos necessários para se elevar a produção ao nível encontrado, a tendência, segundo a teoria utilizada, é que muitos produtores, especialmente pequenos e médios, abandonem a atividade. Um outro fator que agrava a situação é o desconhecimento dos pecuaristas quanto às técnicas de produção e aos processos administrativos, o que dificulta o bom gerenciamento do negócio e a adoção de tecnologias mais adequadas e produtivas. Com efeito, a atividade leiteira em Minas Gerais tem se caracterizado pelo emprego excessivo de recursos e insumos que, no entanto, estão sendo subutilizados ou explorados de forma pouco intensiva (Marques et al., 2002; Fassio, 2004; Ferreira Júnior \& Cunha, 2004; Lopes et al., 2004; Tupy et al., 2005). Há evidências, portanto, de que as empresas estão operando aquém de seu potencial produtivo, dado o nível de recursos disponíveis, o que indica a possibilidade de expansão da produção sem a necessidade de grandes investimentos.

Apesar da teoria econômica indicar a tendência ao abandono da atividade leiteira, verifica-se, na prática, que muitos pecuaristas insistem em permanecer produzindo, mesmo diante de um desempenho econômico insatisfatório. Em face deste comportamento aparentemente contraditório do ponto de vista econômico, se faz necessário tecer alguns comentários acerca das hipóteses capazes de explicá-lo.

Além dos aspectos culturais e da falta de oportunidades em outras atividades, uma das teorias que podem explicar o comportamento observado refere-se à presença de custos irrecuperáveis na exploração leiteira. Segundo esta teoria, o estoque de recursos fixos da atividade possui um valor de aquisição bem superior ao valor de venda ou sucata. Assim, mesmo numa situação de custos elevados e baixos preços recebidos, o produtor, em razão do baixo valor de revenda, não se desfaz do seu estoque de capital, mantendo a atividade em produção como 
uma forma de minimizar os prejuízos, desde que os custos variáveis sejam recuperados.

Um outro fator que explicaria a permanência dos pecuaristas na atividade leiteira refere-se à sua liquidez. A freqüência de recebimentos mensais do leite, assim como a possibilidade da venda de animais, principalmente em rebanhos mistos, colocam à disposição do produtor a liquidez necessária para honrar os compromissos assumidos na propriedade rural. Vale registrar que, segundo os resultados da presente pesquisa, as receitas obtidas com a atividade leiteira foram suficientes, nos estratos de médios e grandes produtores, para pagar todas as despesas de giro da atividade. Isto indica, portanto, que os custos a curto prazo são a referência de grande parte dos produtores no processo de decisão.

Além disso, é importante ressaltar que outras atividades podem estar sendo exploradas nas propriedades, as quais trariam benefícios em função de economias de escopo e complementariam a receita do produtor, minimizando os prejuízos oriundos da atividade leiteira e contribuindo para a sua manutenção no setor rural.

Entretanto, devido à indisponibilidade de dados, não foi possível testar a validade das hipóteses aqui apresentadas, sugerindo-se a realização de estudos que abordem tais aspectos, os quais deveriam também enfocar a dimensão sociológica do problema.

\section{Conclusões}

Neste trabalho, analisaram-se dados de 574 produtores de leite oriundos de todas as regiões do Estado de Minas Gerais, tendo o período de estudo compreendido os anos agrícolas de 1995/96 a 2001/02. A produtividade média diária situou-se em torno de 11 litros/vaca em lactação/dia, indicando baixa eficiência produtiva do plantel. Como conseqüência, os produtores pesquisados incorreram em altos custos por litro de leite produzido, sugerindo ineficiência técnica devido à combinação e alocação inadequada de recursos produtivos, assim como falhas na administração do empreendimento.

Tanto o volume de produção quanto a produtividade foram fatores que influenciaram os custos. Nesse sentido, verificou-se que o custo total médio e a relação custo fixo/custo total apresentaram-se decli- 
nantes com o aumento da produtividade e da escala de produção. Isto demonstra que a eficiência técnica e econômica é alcançada quando o melhor aproveitamento dos fatores de produção conduz ao incremento da produtividade, implicando na diluição dos custos pelo maior volume de leite produzido.

No que diz respeito aos resultados econométricos, como a função de custo variável médio estimada apresentou um ponto mínimo, foi possível estimar o shut-down point da atividade leiteira em Minas Gerais em $\mathrm{R} \$ 0,42$. Este representa o menor preço do produto em que a empresa poderia continuar produzindo e corresponde ao limite de sua resistência quanto ao declínio dos preços recebidos, uma vez que seria suficiente apenas para cobrir os custos variáveis. A esse preço, o pecuarista estaria disposto a ofertar 1.299,45 litros de leite por dia, interrompendo a produção para valores situados abaixo do shut-down point.

Deve-se ressaltar que o resultado da atividade produtiva de leite depende da forma como são gerenciados e alocados os recursos de produção. Em um mercado competitivo, como o setor produtor de leite, a margem de lucro é determinada pela capacidade produtiva da empresa, dadas as condições de preço. Portanto, a atividade leiteira é um empreendimento que exige ganhos de produtividade e escala, conforme evidenciado neste estudo.

\section{Referências Bibliográficas}

ALENCAR, E.; GRANDI, D. S.; ANDRADE, D. M.; ANDRADE, M. P. de. Complexos agroindustriais, cooperativas e gestão. Organizações Rurais e Agroindutriais, Lavras, v. 3, n. 2, p. 30-44, jul./dez. 2001.

FASSIO, L. H. Estrutura de custos e shut-down point da produção leiteira: um estudo em Minas Gerais. 2004. 113 p. Dissertação (Mestrado em Administração) - Universidade Federal de Lavras, Lavras, MG.

FERGUSON, C. E. Microeconomia. 20. ed. Rio de Janeiro: Forense Universitária, 1999. 610 p.

FERREIRA JÚNIOR, S.; CUNHA, N. R. da S. Eficiência técnica na atividade leiteira de Minas Gerais: um estudo a partir de três sistemas de 
produção. Organizações Rurais e Agroindustriais, Lavras, v. 6, n. 2, p. 46-60, jul./dez. 2004.

GOMES, S. T. Intensificar, ou não, o sistema de produção de leite? Viçosa: UFV, 2005. 4 p. Disponível em: www.ufv.br/der/docentes/stg/ stg_artigos.htm. Acesso em: 3 out. 2005.

LEITE, J. L. B.; GOMES, A. T. Perspectivas futuras dos sistemas de produção de leite no Brasil. In: GOMES, A. T.; LEITE, J. L. B.; CARNEIRO, A. V. (Ed.). O agronegócio do leite no Brasil. Juiz de Fora: EMBRAPA/ CNPGL, 2001. p. 207-240.

LOPES, M. A.; LIMA, A. L. R.; CARVALHO, F. de M.; REIS, R. P.; SANTOS, I. C.; SARAIVA, F. H. Controle gerencial e estudo da rentabilidade de sistemas de produção de leite na região de Lavras (MG). Ciência e Agrotecnologia, Lavras, v. 28, n. 4, p. 883-892, jul./ago. 2004.

MARQUES, V. M.; REIS, R. P.; SÁFADI, T.; REIS, A. J. dos. Custos e escala na pecuária leiteira: estudo de casos em Minas Gerais. Ciência e Agrotecnologia, Lavras, v. 26, n. 5, p. 1027-1034, set./out. 2002.

NICHOLSON, W. Microeconomic theory: basic principles and extensions. 7. ed. Fort Worth: Dryden Press, 1998. 821 p.

NOGUEIRA NETTO, V.; MARTINS, M. C.; NERI, C. B. de S. Terra prometida. Agroanalysis, Rio de Janeiro, v. 22, n. 10, p. 46-51, dez . 2002/jan. 2003.

PINDYCK, R. S.; RUBINFELD, D. L. Microeconomia. 5. ed. São Paulo: Prentice Hall, 2002. 711 p.

REIS, R. P. Fundamentos de economia aplicada. Lavras: UFLA/FAEPE, 2002. 95 p.

REIS, R. P.; MEDEIROS, A. L.; MONTEIRO, L. A. Custos de produção da atividade leiteira na região sul de Minas Gerais. Organizações Rurais e Agroindustriais, Lavras, v. 3, n. 2, p. 45-52, jul./dez. 2001.

SERVIÇO DE APOIO ÀS MICRO E PEQUENAS EMPRESAS DE MINAS GERAIS - FEDERAÇÃO DA AGRICULTURA DO ESTADO DE MINAS GERAIS. Diagnóstico da pecuária leiteira do Estado de Minas Gerais: relatório de pesquisa. Belo Horizonte: SEBRAE-MG/FAEMG, 1996. 102 p. 
SOUZA, D. P. H. de. Análise da estrutura de custo e preço de sobrevivência dos principais sistemas de produção de leite. 2000.85 p. Dissertação (Mestrado em Economia Rural) - Universidade Federal de Viçosa, Viçosa, MG.

TUPY, O.; YAMAGUCHI, L. C. T.; MARTINS, P. do C.; CARNEIRO, A. V. A ineficiência custo da produção de leite no Brasil. In: CONGRESSO DA SOCIEDADE BRASILEIRA DE ECONOMIA E SOCIOLOGIA RURAL, 43., 2005, Ribeirão Preto. Anais...Ribeirão Preto: SOBER, 2005. 1 CD-ROM. YAMAGUCHI, L. C. T.; MARTINS, P. do C.; CARNEIRO, A. V. Produção de leite no Brasil nas três últimas décadas. In: GOMES, A. T.; LEITE, J. L. B.; CARNEIRO, A. V. (Ed.). O agronegócio do leite no Brasil. Juiz de Fora: EMBRAPA/CNPGL, 2001. p. 33-48

ZOCCAL, R. Leite em números. In: GOMES, A. T.; LEITE, J. L. B. CARNEIRO, A. V. (Ed.). O agronegócio do leite no Brasil. Juiz de Fora: EMBRAPA/CNPGL, 2001. p. 241-262.

Recebido em junho de 2004 e revisto em novembro de 2005 